\title{
Parâmetros clínicos, hematológicos, bioquímicos e hormonais de bovinos submetidos ao estresse calórico
}

[Clinical, hematological, biochemical, and hormonal parameters of cattle submitted to heat stress]

\author{
F. Ferreira ${ }^{1}$, W.E. Campos $^{2 *}$, A.U. Carvalho ${ }^{2}$, M.F.A. Pires ${ }^{3}$, M.L. Martinez ${ }^{3}$, \\ M.V.G.B. Silva ${ }^{3}$, R.S. Verneque ${ }^{3}$, P.F. Silva ${ }^{4}$ \\ ${ }^{1}$ Aluno de pós-graduação - EV-UFMG - Belo Horizonte, MG \\ ${ }^{2}$ Escola de Veterinária - UFMG - Belo Horizonte, MG \\ ${ }^{3}$ Embrapa Gado de Leite - Juiz de Fora, MG \\ ${ }^{4}$ Bióloga autônoma
}

\begin{abstract}
RESUMO
Caracterizaram-se as respostas clínicas, hematológicas, bioquímicas e hormonais de 71 bovinos $F_{2}(1 / 2$ Gir x 1/2 Holandês), 39 machos e 32 fêmeas, entre 14 e 20 meses de idade, submetidos a condições de termoneutralidade $\left(22^{\circ} \mathrm{C}\right.$ a $70 \%$ de umidade relativa) e ao estresse calórico $\left(42^{\circ} \mathrm{C}\right.$ e $60 \%$ de umidade relativa). Os tratamentos foram realizados nas estações de verão e inverno em câmara bioclimática. Ao exame clínico, todos os animais apresentaram salivação e retração de globo ocular. Os animais apresentaram aumento do número de eritrócitos, concentração de hemoglobina, hematócrito, proteínas totais, ureia, creatinina, sódio, potássio, cloretos, cortisol, $\mathrm{pH}$ e densidade urinária e matéria seca das fezes no período de estresse calórico $(\mathrm{P}<0,05)$. $\mathrm{O}$ aumento de todas essas variáveis foi mais acentuado no verão $(\mathrm{P}<0,05)$. Os valores de $\gamma$-glutamil transferase e aspatato aminotransferase aumentaram no período da tarde no verão $(\mathrm{P}<0,05)$, e a concentração sérica de potássio foi constante entre estações $(\mathrm{P}>0,05)$. Concluiu-se que as variáveis hematológicas, bioquímicas e hormonais, bem como as características fenotípicas, revelaram-se importantes para caracterizar o estresse calórico em bovinos.
\end{abstract}

Palavras-chave: bovino, bioclimatologia, cortisol, desidratação, hematologia

\begin{abstract}
Clinical, haemathological, biochemical, and hormonal parameters were characterized in 39 males and 32 females crossbred cattle (1/2 Holstein $x 1 / 2$ Gir), averaging 14 to 20 months of age, submitted to thermoneutrality $\left(22^{\circ} \mathrm{C}\right.$ and $70 \%$ of $\left.\mathrm{RH}\right)$ and heat stress $\left(42^{\circ} \mathrm{C}\right.$ and $\left.60 \% \mathrm{RH}\right)$ in summer and winter in climatic chamber. At clinical examination, all animals presented salivation and ocular globe retraction. Under heat stress, animals increased erythrocytes count, hemoglobin total concentration, hematocrit, concentraction of total proteins, urea, creatinin, sodium, potassium, chlorides, cortisol, urinary $\mathrm{pH}$ and density, and dry matter of feces $(P<0.05)$. The increase of all these variables was more evident in the summer. The values of $\gamma$-glutamil transferase and aspartate aminotransferase increased under stress only in the summer $(P<0.05)$, been potassium blood concentration constant during the seasons $(P>0.05)$. It was concluded that hematology, biochemical, and hormonal parameters are important to characterize the heat stress in cattle.
\end{abstract}

Keywords: cattle, bioclimatology, cortisol, dehydratation, hematology

\section{INTRODUÇÃO}

O conhecimento da interação entre os animais e o ambiente é fundamental para a tomada de decisões quanto a estratégias de manejo a serem utilizadas para maximizar as respostas produtivas. Dessa forma, o entendimento das variações diárias e sazonais das respostas fisiológicas permite a adoção de ajustes que promovam maior conforto aos animais.

O baixo desempenho produtivo de bovinos, quando associado ao estresse calórico, deve-se principalmente à baixa ingestão de alimentos,

Recebido em 6 de outubro de 2008

Aceito em 27 de março de 2009

*Autor para correspondência (corresponding author)

E-mail: wecampos2@yahoo.com.br 
que é seguida pela diminuição da atividade enzimática oxidativa, da taxa metabólica e da alteração da concentração de vários hormônios (Nardone, 1998; Pereira et al., 2008).

Este trabalho ${ }^{1}$ teve como objetivo caracterizar respostas clínicas, hematológicas, bioquímicas e hormonais de bovinos $F_{2}$ (1/2 Gir x $1 / 2$ Holandês) submetidos ao estresse calórico.

\section{MATERIAL E MÉTODOS}

O número de animais, o local de realização do experimento, o período de estudo e as condições de estresse a que os animais foram submetidos foram descritos por Ferreira et al. (2009).

Foram obtidas duas amostras de sangue de cada animal, pela manhã e à tarde, por venopunção coccígea, para determinação do hematócrito, e realizados esfregaços, que foram fixados e corados pelo método May-Grunwald-Giemsa (Ferreira Neto et al., 1981). O número de eritrócitos foi determinado pela contagem em câmara de Neubauer, conforme Ferreira Neto et al. (1981). Para minimizar o erro, foram realizadas duas contagens de cada parâmetro, sendo cada valor obtido a partir da média dessas contagens. Para a obtenção do soro e do plasma, as amostras foram centrifugadas a 3000 RPM por 15 minutos sendo dosadas no soro as concentrações de proteínas totais, albumina, sódio potássio, cloretos e cortisol; e, nas amostras de plasma, as concentrações de ureia, creatinina, $\gamma$-glutamil transferase (GGT) e aspartato aminotransferase (AST).

As concentrações séricas de proteínas totais foram dosadas pelo método de biureto; a creatinina pelo método de Jaffé modificado; a ureia pelo método enzimático; a enzima AST pelo método de Reitman e Frankel, e a GGT pelo método Naftalin modificado. As leituras foram feitas por espectrofotometria colorimétrica. As dosagens de sódio e potássio foram realizadas por espectrofotometria de chamas, e as de cortisol por radioimunoensaio (RIA) em fase sólida, utilizando-se kit comercial ${ }^{2}$.

${ }^{1}$ Este trabalho fez parte do Projeto "Identificação de marcadores genéticos associados às características de resistência a endo e ectoparasitas e ao estresse térmico em bovinos" da Embrapa Gado de Leite.

${ }^{2}$ Medlab.
As amostras de fezes e urina foram obtidas nos dois períodos, manhã e tarde. Na urina foram realizados exames físicos e químicos. No exame físico, avaliaram-se cor e densidade e, no exame químico, $\mathrm{pH}$, proteína, urobilinogênio, bilirrubina, nitrito, cetona, sangue, ácido ascórbico e glicose. Nas amostras de fezes, foram determinados os teores de matéria seca segundo AOAC (Official..., 1980).

Dados do eritrograma, da bioquímica sanguínea, cortisol e de fezes e urina foram analisados segundo o modelo estatístico: $\mathrm{Y}_{\mathrm{ijklm}}=\mu+\mathrm{E}_{\mathrm{i}}+$ $\mathrm{S}_{\mathrm{j}}+\mathrm{P}_{\mathrm{k}}+\mathrm{e}_{\mathrm{ijk} \mathrm{k}}$, em que: $\mathrm{Y}_{\mathrm{ijklm}}$ é a variável dependente; $\mu$ é a média geral; $E$ é o efeito fixo de estação da medida ( $\mathrm{i}=$ verão, inverno) ${ }_{\mathrm{i}} ; \mathrm{S}_{\mathrm{j}}$ é o efeito fixo de sexo do animal ( $\mathrm{j}=$ macho, fêmea); $\mathrm{P}_{\mathrm{k}}$ é o efeito fixo de período ( $\mathrm{k}=$ manhã, tarde) $\mathrm{e}_{\mathrm{ijkl}}$ é o erro associado a cada observação com $\sim \mathrm{N}\left(0, \sigma^{2}\right)$. Para as análises de correlação entre as variáveis paramétricas usou-se o método de Pearson (Sampaio, 2002). As diferenças entre as médias dos tratamentos propostos foram comparadas adotando-se 5\% de significância. Os resultados foram obtidos utilizando-se $\mathrm{o}$ programa SAS/1988.

\section{RESULTADOS E DISCUSSÃO}

Durante a alocação dos animais dentro da câmara bioclimática, tanto no inverno quanto no verão, obtiveram-se dados constantes de temperatura e umidade. As temperaturas médias registradas nos termômetros de bulbo seco, bulbo úmido e globo negro, no período da manhã, de 22,18 e $23^{\circ} \mathrm{C}$, respectivamente, e o índice de temperatura e umidade (ITU) igual a 69 mostram que os animais permaneceram dentro da faixa de conforto térmico. No período da tarde, esses valores foram mais altos, 43,36 e $44^{\circ} \mathrm{C}$, para os termômetros de bulbo seco, bulbo úmido e globo negro, respectivamente, e o ITU foi igual a 97, índices relatados na literatura como condições de estresse calórico severo (Silva, 2000).

Os valores para eritrócitos, hemoglobina e hematócrito (Tab. 1) revelaram-se mais elevados no período da tarde quando comparados aos do período da manhã $(\mathrm{P}<0,05)$. $\mathrm{O}$ aumento do hematócrito pode ser justificado pelo aumento relativo no número de hemácias (Costa et al., 1985). Esses altos valores revelam que bovinos estressados pelo calor apresentam hemoconcentração causada pela perda de 
líquidos corporais resultante dos mecanismos de dissipação de calor (sudorese e ofego) na tentativa de mantença da temperatura dentro dos limites fisiológicos (Olsson et al., 1995; Srikandakumar e Johnson, 2004). Entretanto, respostas diferentes podem ser verificadas, como as relatadas por Koga et al. (1998) e Brasil et al.
(2000), que observaram diminuição do hematócrito resultante do aumento no consumo de água. Como os animais deste experimento foram privados de água e alimentos, a hemoconcentração ocorreu por desidratação, devido às perdas evaporativas e à não ingestão de água.

Tabela 1. Valores (média \pm EPM) de eritrócitos $\left(10^{6} / \mathrm{mm}^{3}\right)$, hemoglobina $(\mathrm{g} / \mathrm{dL})$ e hematócrito $(\%)$ em bovinos antes (manhã) e após (tarde) o estresse calórico no inverno e no verão

\begin{tabular}{|c|c|c|c|c|c|c|c|c|}
\hline & \multicolumn{3}{|c|}{ Manhã } & \multicolumn{3}{|c|}{ Tarde } & \multirow[b]{2}{*}{ Média geral } & \\
\hline & Macho & Fêmea & Média & Macho & Fêmea & Média & & \\
\hline \multicolumn{9}{|c|}{ Eritrócitos $\left(5-10 \times 10^{6} / \mathrm{mm}^{3}\right) \leftrightarrow$} \\
\hline Inverno & $7,42 \pm 0,15 \mathrm{bB} \Omega$ & $7,87 \pm 0,16 \mathrm{bB} \pi$ & $7,60 \pm 0,11$ & $7,93 \pm 0,15 \mathrm{bA} \Omega$ & $8,24 \pm 0,16 \mathrm{bA} \pi$ & $8,08 \pm 0,11$ & $7,84 \pm 0,08$ & $\mathrm{CV}=11,28$ \\
\hline Verão & $7,84 \pm 0,15 \mathrm{aB} \Omega$ & $9,03 \pm 0,16 \mathrm{aB} \pi$ & $8,43 \pm 0,11$ & $8,70 \pm 0,15 \mathrm{a} A \Omega$ & $9,70 \pm 0,16 \mathrm{a} A \pi$ & $9,20 \pm 0,11$ & $8,82 \pm 0,08$ & $\mathrm{R} 2=0,67$ \\
\hline Média & $7,63 \pm 0,10$ & $8,45 \pm 0,11$ & $8,04 \pm 0,08$ & $8,31 \pm 0,10$ & $8,97 \pm 0,11$ & $8,64 \pm 0,08$ & & \\
\hline \multicolumn{9}{|c|}{ Hemoglobina $(8-12 \mathrm{~g} / \mathrm{dl}) *$} \\
\hline Inverno & $8,69 \pm 0,10 \mathrm{bB} \Omega$ & $8,96 \pm 0,12 \mathrm{bB} \pi$ & $8,78 \pm 0,08$ & $8,81 \pm 0,10 \mathrm{bA} \Omega$ & $9,49 \pm 0,12 \mathrm{bA} \pi$ & $9,25 \pm 0,08$ & $8,81 \pm 0,06$ & $\mathrm{CV}=7,44$ \\
\hline Verão & $8,84 \pm 0,10 \mathrm{aB} \Omega$ & $9,60 \pm 0,12 \mathrm{aB} \pi$ & $9,27 \pm 0,08$ & $9,14 \pm 0,10 \mathrm{aA} \Omega$ & $9,79 \pm 0,12 \mathrm{aA} \pi$ & $9,47 \pm 0,08$ & $9,37 \pm 0,06$ & $\mathrm{R} 2=0,73$ \\
\hline Média & $8,86 \pm 0,07$ & $9,28 \pm 0,08$ & $9,00 \pm 0,06$ & $8,98 \pm 0,07$ & $9,65 \pm 0,08$ & $9,34 \pm 0,06$ & & \\
\hline \multicolumn{9}{|c|}{ Hematócrito $(24-45 \%) \star$} \\
\hline Inverno & $26,00 \pm 0,32 \mathrm{bB} \Omega$ & $26,90 \pm 0,36 \mathrm{bB} \pi$ & $26,24 \pm 0,24$ & $27,33 \pm 0,32 \mathrm{bA} \Omega$ & $27,56 \pm 0,36 \mathrm{bA} \pi$ & $27,45 \pm 0,24$ & $27,07 \pm 0,17$ & $\mathrm{CV}=7,38$ \\
\hline Verão & $26,82 \pm 0,32 \mathrm{aB} \Omega$ & $28,81 \pm 0,36 \mathrm{aB} \pi$ & $27,82 \pm 0,24$ & $28,35 \pm 0,32 \mathrm{aA} \Omega$ & $30,43 \pm 0,36 \mathrm{aA} \pi$ & $29,39 \pm 0,24$ & $28,60 \pm 0,17$ & $\mathrm{R} 2=0,74$ \\
\hline Média & $26,60 \pm 0,23$ & $27,85 \pm 0,25$ & $27,23 \pm 0,17$ & $27,84+0,23$ & $29,00 \pm 0,25$ & $28,42 \pm 0,17$ & & \\
\hline
\end{tabular}

Médias seguidas por letras distintas minúsculas na coluna e maiúsculas na linha indicam diferença entre estações e entre períodos, respectivamente $(\mathrm{P}<0,05)$.

Médias seguidas por letras gregas distintas na linha indicam diferença entre sexos $(\mathrm{P}<0,05)$.

* Valores entre parênteses são os de referência para bovinos, para a variável descrita.

Os resultados referentes a eritrócitos, hemoglobina e hematócrito em relação às estações mostram que esses parâmetros apresentaram-se mais elevados no verão quando comparados aos do inverno. Estes achados podem estar relacionados aos mecanismos termorreguladores mais utilizados nas estações mais quentes, como evapotranspiração e taquipneia. A diferença do número de eritrócitos, concentração de hemoglobina e hematócrito entre os períodos da manhã e da tarde foram maiores no verão (Fig. 1). Essa resposta, provavelmente, deveu-se ao fato de as temperaturas mais altas no verão estarem associadas à elevação da temperatura corporal.

As médias de temperatura e umidade ambiente para os períodos de verão e inverno foram $23,2^{\circ} \mathrm{C}$ e $69,8 \%$ e $18,6^{\circ} \mathrm{C}$ e $71,9 \%$, respectivamente. Os valores mensais de máximas e mínimas foram citados por Ferreira et al. (2006).
O aumento nos valores de eritrócitos, hemoglobina e hematócrito e a alta correlação entre esses $(0,76$ a 0,98$)$ confirmam a hipótese de desidratação dos animais, uma vez que tal situação ocorre nos casos de perda de líquido extracelular (LEC).

A análise de variância revelou interação de época versus sexo para número de eritrócitos, hemoglobina e hematócrito. Neste estudo, as fêmeas apresentaram maiores variações na estação do verão, o que sugere que essa categoria animal foi mais afetada com o processo de desidratação quando comparadas aos machos. No período da manhã, tanto na estação do verão quanto na do inverno, nenhum animal apresentou salivação, boca aberta, exposição de língua ou retração do globo ocular (RGO). Já no período da tarde, todos os animais apresentaram algum sinal clínico, demonstrando estar sob influência 
do estresse calórico. Durante o período da tarde, no inverno, dois animais abriram a boca e apenas um expôs a língua. No verão, quatro animais abriram a boca e três animais expuseram a língua.

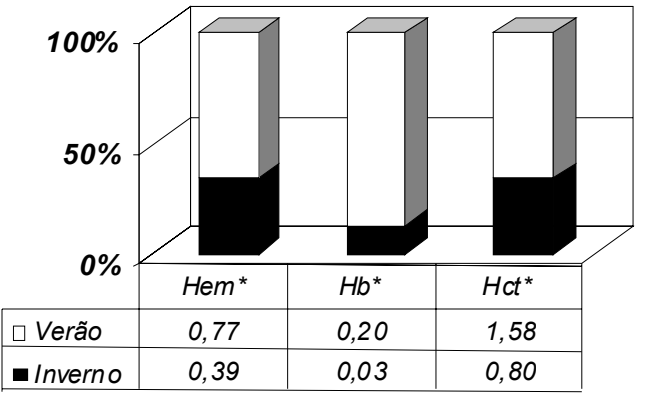

Figura 1. Concentrações de eritrócitos (Hem), hemoglobina $(\mathrm{Hb})$ e hematócrito (Hct) entre os períodos da manhã e da tarde, segundo as estações.

Apesar de estarem sob intenso estresse calórico, todos os animais suportaram o tempo de exposição de seis horas dentro da câmara climática, a despeito de apresentarem sinais evidentes de estresse, salivação, retração de globo ocular e exposição da língua e conseguiram ficar em estação. Não foram registradas mortes. Experimentos realizados com novilhos da raça Holandesa em câmara climática mostraram que animais expostos à temperatura ambiente de $42^{\circ} \mathrm{C}$ e $60 \%$ de umidade (Terui et al., 1979) e $42^{\circ} \mathrm{C}$ e $80 \%$ de umidade (Terui et al., 1980) não suportaram o estresse calórico e vieram a óbito entre quatro e seis horas de exposição. Isto demonstra que, mesmo com a exposição às temperaturas e umidades elevadas e letais para bovinos europeus, os animais deste experimento apresentam maior rusticidade e/ou adaptação ao ambiente tropical e, consequentemente, suportaram melhor o estresse calórico.

As concentrações plasmáticas de proteínas totais, albumina, creatinina, ureia, GGT, AST, íons sódio $\left(\mathrm{Na}^{+}\right)$, íons potássio $\left(\mathrm{K}^{+}\right)$e íons cloretos $\left(\mathrm{Cl}^{-}\right)$(Tab.2) foram afetadas pelo estresse calórico agudo, com aumento de todas essas variáveis no período da tarde $(\mathrm{P}<0,05)$. Houve também efeito da estação que resultou em valores mais elevados no verão $(\mathrm{P}<0,05)$, exceto para a concentração de $\mathrm{K}^{+}$e de $\mathrm{Cl}^{-}$, sendo que este último apresentou maior concentração no inverno $(\mathrm{P}<0,05)$.

Embora dentro dos limites da normalidade, o aumento nas concentrações de proteínas totais (PT), albumina, ureia, creatinina no período da tarde ocorreu devido à hemoconcentração ocasionada pela desidratação provocada pelo estresse calórico agudo. A causa mais comum do aumento de PT e albumina em bovinos é a desidratação. Esse aumento secundário à desidratação é, geralmente, acompanhado pelo aumento nos valores de hematócrito (Cole et al., 1997), fato que se observou nos animais deste experimento (Tab. 1). Embora a GGT e a AST não sejam tão sensíveis às variações nas concentrações de líquido plasmático, quando comparadas ao hematócrito e às proteínas totais (Burtis e Ashwood, 1998), aquelas variáveis seguiram o mesmo comportamento destas.

O aumento das concentrações de ureia e creatinina nos animais estressados pode ser atribuído ao aumento do catabolismo proteico (Ronchi et al., 1995) ou à diminuição da perfusão renal resultante da diminuição do líquido extracelular (LEC), o que leva à incapacidade de filtração normal da creatinina pelos rins (Srikandakumar e Johnson, 2004).

Embora tenha ocorrido aumento nas concentrações de sódio, potássio e cloretos no período da tarde, tais valores mantiveram-se dentro da faixa de referência para bovinos (Tab. 2). A hipernatremia é, muitas vezes, atribuída à perda excessiva de líquidos pobres em $\mathrm{Na}^{+}$, isto é, à perda de água não proporcional à perda de $\mathrm{Na}^{+}$. Esta condição pode ocorrer em casos de suor profuso, hiperpneia prolongada e poliúria, sinais estes constatados nos animais deste experimento durante o estresse agudo. Além disso, a produção aumentada de mineralocorticoides em animais sob estresse pode acarretar no aumento da reabsorção tubular de $\mathrm{Na}^{+}$e aumento concomitante nas concentrações plasmáticas deste íon (Burtis e Ashwood, 1998). 
Tabela 2. Proteínas totais $(\mathrm{g} / \mathrm{dL})$, albumina $(\mathrm{g} / \mathrm{dL})$, creatinina $(\mathrm{mg} / \mathrm{dL})$, uréia $(\mathrm{mg} / \mathrm{dL}), \gamma$-glutamil transferase $(\mathrm{U} / \mathrm{L})$, aspartato aminotransferase $(\mathrm{U} / \mathrm{L})$, sódio $(\mathrm{mEq} / \mathrm{L})$, potássio $(\mathrm{mEq} / \mathrm{L})$ e cloretos $(\mathrm{mEq} / \mathrm{L})$ em bovinos antes (manhã) e após (tarde) o estresse calórico nas estações de inverno e verão (média \pm EPM)

\begin{tabular}{|c|c|c|c|c|}
\hline & Manhã & Tarde & Média & \\
\hline \multicolumn{5}{|c|}{ Proteínas totais $(6,5-8,5 \mathrm{~g} / \mathrm{dL}) \propto$} \\
\hline Inverno & $8,33 \pm 0,05 \mathrm{~B}$ & $8,55 \pm 0,05 \mathrm{bA}$ & $8,43 \pm 0,04$ & $\mathrm{CV}=5,13$ \\
\hline Verão & $8,34 \pm 0,05 \mathrm{~B}$ & $8,87 \pm 0,05 \mathrm{aA}$ & $8,60 \pm 0,04$ & $\mathrm{R}^{2}=0,70$ \\
\hline \multicolumn{5}{|c|}{ Albumina $(2-4 g / d L) \propto$} \\
\hline Inverno & $2,27 \pm 0,02 \mathrm{~B}$ & $2,36 \pm 0,02 \mathrm{bA}$ & $2,32 \pm 0,02$ & $\mathrm{CV}=8,49$ \\
\hline Verão & $2,30+0,02 \mathrm{~B}$ & $2,51+0,02 \mathrm{aA}$ & $2,41+0,02$ & $\mathrm{R}^{2}=0,68$ \\
\hline \multicolumn{5}{|c|}{ Creatinina $(1-2 \mathrm{mg} / \mathrm{dL}) \propto$} \\
\hline Inverno & $1,25 \pm 0,02 \mathrm{~B}$ & $1,35 \pm 0,02 \mathrm{bA}$ & $1,30 \pm 0,04$ & $\mathrm{CV}=14,56$ \\
\hline Verão & $1,31 \pm 0,02 \mathrm{~B}$ & $1,51 \pm 0,02 \mathrm{aA}$ & $1,41 \pm 0,04$ & $\mathrm{R}^{2}=0,64$ \\
\hline \multicolumn{5}{|c|}{ Ureia $(10-45 \mathrm{mg} / \mathrm{dL}) \propto$} \\
\hline Inverno & $24,72+0,52 \mathrm{~B}$ & $29,27 \pm 0,52 \mathrm{bA}$ & $26,99 \pm 0,37$ & $\mathrm{CV}=15,38$ \\
\hline Verão & $26,07+0,52 \mathrm{~B}$ & $32,75 \pm 0,52 \mathrm{aA}$ & $29,41+0,37$ & $\mathrm{R}^{2}=0,69$ \\
\hline \multicolumn{5}{|c|}{ GGT $(0-50 U / L)+$} \\
\hline Inverno & $16,57 \pm 0,70$ & $17,27 \pm 0,70 \mathrm{~b}$ & $16,92 \pm 0,50$ & $\mathrm{CV}=32,87$ \\
\hline Verão & $17,54 \underline{-0,70 \mathrm{~B}}$ & $20,84 \pm 0,70 \mathrm{aA}$ & $19,19 \pm 0,50$ & $\mathrm{R}^{2}=0,55$ \\
\hline \multicolumn{5}{|c|}{$\operatorname{AST}(13-110 \mathrm{U} / \mathrm{L})$} \\
\hline Inverno & $50,04+0,89$ & $50,09 \pm 0,89 \mathrm{~b}$ & $50,07 \pm 0,63$ & $\mathrm{CV}=14,20$ \\
\hline Verão & $52,13+0,89 \mathrm{~B}$ & $57,03+0,89 \mathrm{aA}$ & $55,09+0,63$ & $\mathrm{R}^{2}=0,61$ \\
\hline \multicolumn{5}{|c|}{ Sódio $(130-145 \mathrm{mEq} / \mathrm{L})$ ↔ } \\
\hline Inverno & $132,55 \pm 0,42 \mathrm{bB}$ & $134,78 \pm 0,42 \mathrm{bA}$ & $133,66 \pm 0,30$ & $\mathrm{CV}=2,59$ \\
\hline Verão & $135,38 \pm 0,42 \mathrm{aB}$ & $138,82 \pm 0,42 \mathrm{aA}$ & $137,10 \pm 0,30$ & $\mathrm{R}^{2}=0,57$ \\
\hline \multicolumn{5}{|c|}{ Potássio $(3,5-5 \mathrm{mEq} / \mathrm{L}) \propto$} \\
\hline Inverno & $4,06+0,04 \mathrm{~B}$ & $4,18+0,04 \mathrm{~A}$ & $4,12 \pm 0,02$ & $\mathrm{CV}=7,09$ \\
\hline Verão & $4,08 \pm 0,04 \mathrm{~B}$ & $4,24 \pm 0,04 \mathrm{~A}$ & $4,16+0,02$ & $\mathrm{R}^{2}=0,53$ \\
\hline \multicolumn{5}{|c|}{ Cloretos $(90-110 \mathrm{mEq} / \mathrm{L})$} \\
\hline Inverno & $97,20 \pm 0,55 \mathrm{aB}$ & $104,37 \pm 0,55 \mathrm{aA}$ & $100,28 \pm 0,40$ & $\mathrm{CV}=4,65$ \\
\hline Verão & $95,43 \pm 0,55 \mathrm{bB}$ & $102,09 \pm 0,55 \mathrm{bA}$ & $98,76 \pm 0,40$ & $\mathrm{R}^{2}=0,58$ \\
\hline
\end{tabular}

Médias seguidas por letras distintas minúsculas na coluna e maiúsculas na linha diferem entre si $(\mathrm{P}<0,05)$.

* Valores entre parênteses são os de referência para bovinos para a variável descrita. EPM: erro-padrão da média.

$\mathrm{O}$ aumento das concentrações de $\mathrm{K}^{+}$após a exposição ao calor pode ter advindo da transferência de $\mathrm{K}^{+}$do líquido intracelular (LIC) para o LEC, o que pode ocorrer nos casos de desidratação e choque com hipóxia tecidual (Burtis e Ashwood, 1998), fatos estes observados nos animais.

A hipercloremia observada, provavelmente, ocorreu como resultante da desidratação, embora leve aumento da concentração de cloretos também possa ser observado na alcalose respiratória (Burtis e Ashwood, 1998), quadro comumente encontrado em animais em estresse calórico. $\mathrm{O}$ aumento do $\mathrm{Cl}^{-}$deprime a excreção de $\mathrm{H}^{+}$e a reabsorção de $\mathrm{HCO}_{3}^{-}$pelos rins. Isso pode contribuir com a acidificação do sangue, e esta parece ser uma resposta apropriada à alcalose. Entretanto, há de se considerar que o tempo de estresse reduz a concentração sérica de $\mathrm{Cl}^{-}$quando as condições expostas são de estresse crônico (Das et al., 1997; Marai et al., 1999). 
Este fato pode explicar a concentração sérica de $\mathrm{Cl}^{-}$mais baixa nos animais deste experimento durante a estação do verão.

As concentrações de cortisol apresentam-se dentro da faixa de normalidade para bovinos (Tab. 3). Houve variação entre as estações do verão e do inverno, mais elevadas no verão $(\mathrm{P}<0,05)$, e entre sexos, com as fêmeas apresentando concentrações séricas mais elevadas $(\mathrm{P}<0,05)$. A diferença entre períodos foi observada para fêmeas somente na estação do verão, em que verificou aumento significativo nas concentrações de cortisol no período da tarde $(\mathrm{P}<0,05)$. Possivelmente, o aumento nas concentrações séricas de cortisol entre períodos resultou do estresse calórico agudo, uma vez que esse hormônio é um dos indicadores de estresse. Períodos de flutuação deste hormônio ao longo do tempo parecem influenciar o processo de adaptação dos animais a um agente estressor não específico (Correa-Calderon et al., 2004)

Tabela 3. Concentração de cortisol ( $\mu \mathrm{g} / \mathrm{dL})$ antes (manhã) e após (tarde) o estresse calórico nas estações de inverno e verão (média \pm EPM)

\begin{tabular}{|c|c|c|c|c|c|c|c|}
\hline & \multicolumn{6}{|c|}{ Cortisol $(2-6 \mu \mathrm{g} / \mathrm{dL})$} & \multirow{3}{*}{$\begin{array}{l}\text { Média } \\
\text { Geral }\end{array}$} \\
\hline & \multicolumn{3}{|c|}{ Manhã } & \multicolumn{3}{|c|}{ Tarde } & \\
\hline & Macho & Fêmea & Média & Macho & Fêmeas & Média & \\
\hline Inverno & $2,42 \pm 0,29 \mathrm{~b} \pi$ & $3,02 \pm 0,32 \mathrm{~b} \Omega$ & $2,71 \pm 0,21$ & $3,04 \pm 0,29 b$ & $3,57 \pm 0,32 b$ & $3,31 \pm 0,21$ & $3,01 \pm 0,15$ \\
\hline Verão & $3,87 \pm 0,37 \mathrm{a} \pi$ & $5,07 \pm 0,39 \mathrm{aB} \Omega$ & $4,48 \pm 0,27$ & $4,13 \pm 0,37 \mathrm{a} \pi$ & $6,02 \pm 0,39 \mathrm{aA} \Omega$ & $5,07 \pm 0,27$ & $4,77 \pm 0,20$ \\
\hline Média & $3,13 \pm 0,23$ & $4,06 \pm 0,25$ & $3,59+0,17$ & $3,60 \pm 0,23$ & $4,78+0,25$ & $4,19+0,17$ & \\
\hline
\end{tabular}

$\mathrm{CV}=49,71$ e $\mathrm{R}^{2}=0,61$.

Médias seguidas por letras distintas minúsculas na coluna e maiúsculas na linha indicam diferenças entre estações e entre períodos, respectivamente $(\mathrm{P}<0,05)$.

Médias seguidas por letras gregas distintas na linha indicam diferenças entre sexos $(\mathrm{P}<0,05)$.

* Valores entre parênteses são os de referência para bovinos para a variável descrita. EPM: erro-padrão da média.

A matéria seca das fezes foi de $16,0 \%$ no período da manhã e de $18,2 \%$ no período da tarde (Tab. 4), demonstrando maior perda de água neste período quando comparado àquele $(\mathrm{P}<0,05)$. Esse fato pode ser explicado pela desidratação dos animais e consequente diminuição do LEC, que, assim, ativou o sistema nervoso central e desencadeou o aumento da absorção de água no intestino grosso e a retenção deste líquido no organismo.

Em relação à coleta de urina, observou-se maior dificuldade de coleta no período da tarde, tanto no verão como no inverno. Ao exame físico, observou-se coloração mais escura no período da tarde. A densidade também variou entre os períodos da manhã e da tarde, sendo que essa se apresentou mais elevada no período da tarde, 1.039 (Tab. 4). Em relação às estações, podem-se observar fezes mais ressecadas e densidade urinária mais elevada na estação do inverno $(18,8 \%$ e 1.041$)$ do que no verão $(17,7 \%$ e 1.037). Assim, pode-se afirmar que há maior capacidade de retenção de água no organismo dos animais na estação do inverno (maior capacidade absortiva intestinal de água e maior capacidade de concentrar a urina) que pode ser explicada pelo menor grau de desidratação apresentado pelos animais durante esta estação.

O exame químico foi realizado e não foram observadas diferenças entre períodos ou estações nas concentrações de urobilinogênio, bilirrubina, nitrito, cetona, sangue, ácido ascórbico e glicose. $\mathrm{O}$ pH foi mais alto no período da tarde (Tab. 4), o que pode ser atribuído à maior excreção de íons $\mathrm{HCO}_{3}^{-}$na urina, proveniente $\mathrm{da}$ hemoconcentração deste íon. Uma das respostas fisiológicas ao estresse calórico é o aumento da frequência respiratória, o que resulta em perdas excessivas de $\mathrm{CO}_{2}$ pela respiração. Assim a pressão parcial de $\mathrm{CO}_{2}$ sanguínea diminui, levando à queda na concentração de $\mathrm{H}_{2} \mathrm{CO}_{3} \mathrm{e}$ íons $\mathrm{H}^{+}$. Em resposta, os rins aumentam a excreção de $\mathrm{HCO}_{3}{ }^{-}$e reduzem a excreção de íons $\mathrm{H}^{+}$na tentativa de manter o equilíbrio ácido-base (Beatty et al., 2006). 
Tabela 4. Matéria seca (\%) das fezes, densidade e pH da urina de bovinos antes (manhã) e após (tarde) o estresse calórico nas estações de inverno e verão (média \pm EPM)

\begin{tabular}{ccccc} 
& \multicolumn{3}{c}{ Matéria seca $(11-20 \%) *$} & \\
\cline { 2 - 4 } & Manhã & Tarde & Média & \\
\hline Inverno & $15,90 \pm 0,36 \mathrm{~B}$ & $18,81 \pm 0,35 \mathrm{aA}$ & $17,36 \pm 0,25$ & $\mathrm{CV}=16,48$ \\
Verão & $16,09 \pm 0,35 \mathrm{~B}$ & $17,66 \pm 0,36 \mathrm{bA}$ & $16,87 \pm 0,25$ & $\mathrm{R}^{2}=0,53$ \\
Média & $15,99 \pm 0,25$ & $18,24 \pm 0,25$ & \\
\hline \multicolumn{5}{c}{ Densidade $(1.020-1.040) *$} \\
Inverno & $1029,52 \pm 1,03 \mathrm{~B}$ & $1041,54 \pm 1,03 \mathrm{aA}$ & $1035,5 \pm 0,78$ & $\mathrm{CV}=0,62$ \\
Verão & $1026,39 \pm 1,27 \mathrm{~B}$ & $1037,63 \pm 1,27 \mathrm{bA}$ & $1032,0 \pm 0,99$ & $\mathrm{R}^{2}=0,70$ \\
Média & $1027,96 \pm 0,77$ & $1039,59 \pm 0,77$ & \\
\hline \multicolumn{5}{c}{$\mathrm{pH}(7,0-8,0) *$} \\
Inverno & $7,34 \pm 0,07 \mathrm{~B}$ & $8,27 \pm 0,07 \mathrm{aA}$ & $7,81 \pm 0,05$ & $\mathrm{CV}=5,47$ \\
Verão & $7,26 \pm 0,08 \mathrm{~B}$ & $8,03 \pm 0,08 \mathrm{bA}$ & $7,64 \pm 0,06$ & $\mathrm{R}^{2}=0,80$ \\
Média & $7,30 \pm 0,05$ & $8,15 \pm 0,05$ & \\
\hline
\end{tabular}

Médias seguidas por letras distintas minúsculas na coluna e maiúsculas na linha diferem entre si $(\mathrm{P}<0,05)$.

* Valores entre parênteses são os de referência para bovinos para as variáveis descritas acima. EPM: erro-padrão da média.

A correlação entre $\mathrm{o} \quad \mathrm{pH}$ urinário $\mathrm{e}$ as concentrações séricas de $\mathrm{K}^{+}$foi negativa $(\mathrm{r}=$ $0,37)$ e significativa $(\mathrm{P}<0,001)$. Quanto maior o $\mathrm{pH}$ da urina, menor concentração sérica de $\mathrm{K}^{+}$, pois a alcalose respiratória favorece a excreção de $\mathrm{K}^{+}$na urina. $\mathrm{O}$ estresse calórico também pode influenciar a liberação de mineralocorticoides, sendo que a aldosterona pode atuar de duas maneiras nos rins. $\mathrm{O}$ aumento da secreção de potássio pode ser atribuído à resposta do segmento conector e do ducto coletor ao estímulo da bomba de $\mathrm{Na}^{+} / \mathrm{K}^{+}$ATPase, mas, também, ao efeito direto da aldosterona nesses locais, aumentando a permeabilidade da membrana apical ao $\mathrm{K}^{+}$. Portando, indiferente do estímulo para a sua liberação, a aldosterona aumenta a reabsorção de $\mathrm{Na}^{+}$e a secreção de $\mathrm{K}^{+}$ no segmento conector e ducto coletor (Burtis e Ashwood, 1998).

Os graus de proteinúria no período da manhã variaram de 0 a 1 , permanecendo assim entre os valores normais. No período da tarde observouse aumento das concentrações de proteínas na urina (Fig. 2). Como a coleta foi realizada por micção natural, não foi possível obter amostra de todos os animais. No inverno foram coletadas amostras de 43 animais $(56,6 \%)$ e no verão, de $33(43,4 \%)$. Nenhum animal apresentou proteína grau 0 na urina no período da tarde, tanto no verão quanto no inverno. Nas amostras coletadas no verão, no período da tarde, observou-se que
$12 \%, 25 \%$ e $63 \%$ dos animais apresentaram proteinúria graus 1,2 e 3 , respectivamente. $\mathrm{Na}$ estação de inverno, essas porcentagens foram de $15 \%, 55 \%$ e $30 \%$, respectivamente. Esses dados mostram maior concentração de proteínas na urina (grau 3) dos animais durante o verão.

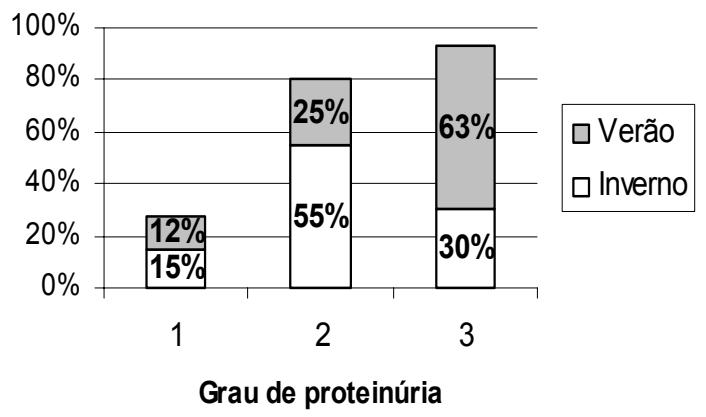

Figura 2. Porcentagem de animais com concentração de proteína na urina grau $1(+), 2$ $(++)$ ou $3(+++)$ no período de estresse nas estações de inverno e verão.

Esse aumento de proteínas pode ser decorrente de lesão dos túbulos renais e descamação celular para o lúmen tubular. Terui et al. $(1979,1980)$, ao avaliarem a resistência de bovinos da raça Holandesa ao estresse calórico, observaram que a $42^{\circ} \mathrm{C}$ e $60 \%$ ou $80 \%$ de umidade os animais vieram a óbito entre quatro e seis horas de exposição, sendo que, no exame histopatológico, 
estes animais apresentaram lesão de tecidos em vários órgãos, entre eles o tecido renal, e que esta foi descrita como degeneração e princípio de necrose tubular.

\section{CONCLUSÕES}

As variáveis, hematológicas, bioquímicas e hormonais, bem como características fenotípicas mostraram-se de grande importância para caracterizar o estresse calórico em bovinos

\section{REFERÊNCIAS BIBLIOGRÁFICAS}

BEATTY, D.T.; BARNES, A.; TAYLOR, E. et al. Physiological responses of Bos taurus and Bos indicus cattle to prolonged, continuous heat and humidity. $J$. Anim. Sci., v.84, p.972-985, 2006.

BRASIL, L.H.A.; WECHESLER, F.S.; BACCARI Jr., F. et al. Efeito do estresse térmico sobre a produção, composição química do leite e respostas termorreguladoras de cabras da raça Alpina. Rev. Bras. Zootec., v.29, p.1632-1641, 2000.

BURTIS, C.A.; ASHWOOD, E.R. Fundamentos de química clínica. 4.ed. Rio de Janeiro: Guanabara Koogan, 1998. 836p.

COLE, J.D.; ROUSSEL, A.J.; WHITNEY, M.S. Interpretating a bovine $\mathrm{CBC}$ : collecting a sample and evaluating eritron. Vet. Med., v.92, p.460-468, 1997.

CORREA-CALDERON, A.; ARMSTRONG, D.; RAY, D. et al. Thermoregulatory responses of Holstein and Brown Swiss heat-stressed dairy cows to two different cooling systems. Int. J. Biometeorol., v. 48, p. $142-148,2004$

COSTA, M.J.R.P.; TONHATI, H.; OLIVEIRA, P.S.P.F. et al. Polimorfismo da hemoglobina, hematócrito e taxa de hemoglobina em vacas Jersey. Vet. Zootec., v.1, p.23-30, 1985.

DAS, U.; ROY, S.; ROY, B.N. et al. Some blood constituents of crossbred cattle in two agro-climate zones of West Bengal. Indian J. Anim. Health, v.36, p.11-13, 1997.

FERREIRA, F.; CAMPOS, W.E.; CARVALHO, A.U. et al. Taxa de sudação e parâmetros histológicos de bovinos submetidos ao estresse calórico. Arq. Bras. Med. Vet. Zootec., v.61, p.763-768, 2009.

FERREIRA, F.; PIRES, M.F.A.; MARTINEZ, M.L. et al. Parâmetros fisiológicos de bovinos cruzados submetidos ao estresse calórico. Arq. Bras. Med. Vet. Zootec., v.58, p.732-738, 2006.
FERREIRA NETO, J.M.; VIANA, E.S.; MAGALHÃES, L.M. Patologia clínica veterinária. Belo Horizonte: Rabelo, 1981. 279p.

KOGA, A.; KURATA, K.; FURUKAWA, R. et al. Rectal skin temperature difference regulated by blood volume in swamp buffaloes in hot conditions: comparative study of thermoregulation in buffaloes and cattle. Anim. Sci. Tech., v.69, p.81-89, 1998.

MARAI, I.F.M.; HABEEB, A.A.M.; FARGHALY, H.M. Productive, physiological and biochemical changes in imported an locally born Holstein lactating cows under hot summer conditions of Egypt. Trop. Anim. Health Prod., v.31, p.233-243, 1999.

NARDONE, A. Thermoregulatory capacity among selection objectives in dairy cattle in hot environment. Zootec. Nutr. Anim., v.24, p.295-306, 1998.

OFFICIAL methods of analysis. Washington, DC: AOAC, 1980. 1015p.

OLSSON, T.A.; HERMELIN-JOSATER, M.; KANN, G. et al. Heat stress causes excessive drinking in fed and food deprived pregnant goats. Comp. Bioch. Phys., v.10, p.309-317, 1995.

PEREIRA, A.M.; BACCARI Jr., F.; TITTO, E.A. et al. Effect of thermal stress on physiological parameters, feed intake and plasma thyroid hormones concentration in Alentejana, Mertolenga, Frisian and Limousine cattle breeds. Int. J. Biometeorol., v.52, p.199-208, 2008.

RONCHI, B.; BERNABUCCI, U.; LACETERA, N.G. et al. Effetti dello "stress" térmico sullo stato metabólico di vitelle di razza frizona. Zoot. Nutr. Anim., v.21, p.209-221, 1995.

SAMPAIO, I.B.M. Estatística aplicada à experimentação animal. Belo Horizonte: FERPMVZ, 2002. $265 \mathrm{p}$

SILVA, R.G. Introdução à bioclimatologia animal. São Paulo: Nobel, 2000. 286p.

SRIKANDAKUMAR, A.; JOHNSON, E.H. Effect of heat stress on milk production, rectal temperature, respiratory rate and blood chemistry in Holstein, Jersey and Australian Milking Zebu cows. Trop. Anim. Health Prod., v.36, p.685-692, 2004.

TERUI, S.; ISHINO, S.; MATSUDA, K. et al. Clinical, hematological and phathological responses in severely heat-stressed steers with especial reference to the threshold value for survival. Nat. Inst. Anim. Health Quat., v.20, p.138-147, 1980.

TERUI, S.; ISHINO, S.; MATSUDA, K. et al. Effect of experimental high environmental temperature and humidity on steers. Tohoku J. Agric. Res., v.30, p.95$109,1979$. 